\title{
Effectiveness of Group Therapy Based on Transactional Analysis (TA) in Marital Burnout and Forbearance of Female Students
}

\author{
Sedigheh Sakaki, Toozandehjani Hassan* \\ Department of Psychology, Faculty of Humanities, Neyshabur Branch, Islamic Azad University, Neyshabur, Iran \\ Email: *H.Toozandehjani@ymail.com
}

How to cite this paper: Sakaki, S. and Hassan, T. (2017) Effectiveness of Group Therapy Based on Transactional Analysis (TA) in Marital Burnout and Forbearance of Female Students. Open Journal of Medical Psychology, 6, 76-85.

https://doi.org/10.4236/ojmp.2017.62006

Received: November18, 2016

Accepted: April 17, 2017

Published: April 20, 2017

Copyright ( 92017 by authors and Scientific Research Publishing Inc. This work is licensed under the Creative Commons Attribution International License (CC BY 4.0).

http://creativecommons.org/licenses/by/4.0/

\begin{abstract}
This research is a semi-experimental study (pretest-posttest design with unequal control group). This study aimed to investigate the effectiveness of the group therapy based on transactional analysis in marital burnout and forbearance of married female students. The research on statistical population comprised all married female students studying in humanities subjects in Neishabour Islamic Azad University in the academic year 2015-16. The sample included 24 of these students, who were selected voluntarily and through Random sampling method and were randomly assigned into two experimental and control groups. Measurement tools consisted of Couple Burnout Measure (CBM) and Evans marital forbearance questionnaire. The experimental group received 10 one-half hour sessions of the treatment based on the transactional analysis whereas in the meantime, the control group received nutritional trainings. The results indicated that the therapy based on the transactional analysis had been effective in reducing marital burnout and increasing the forbearance of couples.
\end{abstract}

\section{Keywords}

Group Therapy, Transactional Analysis (TA),

Marital Burnout and Forbearance

\section{Introduction}

Despite all the conservative approaches to family institution, it is observed that this institution has experienced tremendous structural and functional changes over the last century. These changes have been caused by different transformational factors and elements [1]. On the other hand, the latest statistics show that the divorce rate is rising in the West, especially America [2]. The same statistics 
have also had an upward trend in Iran so that the divorce rate in the first four months of 2012 compared to the same period in 2011 had had 10\% growth while the marriage rate had increased by $3 \%$ [3].

Studies demonstrate that one of the factors which over time have managed to reduce or eliminate the love and interest between couples and caused mental health problems and continued cold and indifferent relationships and finally completion of a relationship is marital burnout [4]. The research done by family experts shows that the prevalence of marital burnout has increased today such that $50 \%$ of couples encounter burnout in their marriage [5]. Burnout is the painful state of physical, emotional and psychological exhaustion that affects those who expect dramatic love makes their life meaningful. This state occurs when they notice that despite all their efforts, their life is not meaningful and will not become so [6]. Marital burnout is physical, emotional and psychological exhaustion that originates from the mismatch between expectations and reality. Accumulation of psychological pressures that weaken the love, gradual increase of fatigue, monotony of life and accumulation of small annoyances helps the incidence of burnout [7].

[8] believes that disturbance of the relationship between a couple is not directly related to the behaviors of the other side or hard failures of life, but it is mostly due to the beliefs and opinions that this couple holds in connection with such behaviors and failures since it is thinking the belief which widely leads to either anger and turbulent relationship of couples or patience and forbearance. Thinking, feeling and behavior are interacting with each other and affect and take the influence from one another [9].

\section{Literature Review}

1) Some research on marital burnout should be reported.

Each individual's perception of the situation and the act performed by the person can be associated with one of the characteristics of his personality, i.e. forbearance, since forbearance is a way for human resistance in difficult circumstances which refers to human endurance and resistance against delay or stimulating opportunities without causing annoyance or anger or other negative ways. Forbearance is a manifestation of patience of every human being when he is under pressure, especially when faced with long-term problems. Forbearance is a level of individual tolerance before he shows a negative reaction. Additionally, this term is applied to refer to the quality of consistency in individuals. In evolutionary psychology and cognitive neuroscience, forbearance has been examined as a difficult decision between two choices (e.g. choosing a small reward in the short term or choosing a more valuable reward in the long run). In all organisms, the tendency to get short-term rewards is greater than long-term rewards although mostly long-term rewards have more benefits compared to short-term rewards [10].

One of the theories that have effective applications in improving human relations is the theory of Transactional Analysis. Transactional analysis is one of the 
most tangible theories of modern psychology. This theory was proposed by Eric Berne and is widely used with the constructs of parenthood I, adulthood I, childhood I in clinical, therapeutic and organizational affairs and in growth psychology, communication, management, personality, relations and behavior [11].

Relationship analysis is basically used in marital relations and social bonds. In these situations, relationship analysis can provide beneficial and satisfactory forecasts and reviews. In relationship analysis, consideration is further given to human relationships with each other and it is believed that if people have healthy, positive and satisfactory relationships with each other and replace destructive, negative and degrading relationships with them, they will be able to reduce their own and other's mental pressures and take more pleasure from their life [12]. According to [13], transactional analysis is one of the most effective psychological theories that help the growing trend of happiness in people through solving the problems in human relations.

2) Several studies on marital forbearance should be reported.

Numerous studies have demonstrated the effectiveness of transactional analysis in improving the emotional breakdown of students [14], personality states, self-esteem and clinical symptoms of people with emotional breakdown [12], reducing marital conflicts [7], marital satisfaction [5], methods of coping with stress [13], preventing the increase of conflict and violence [6], development of communication skills, understanding of others and self-expression [2] and marital intimacy [3]. Many researches have investigated the effectiveness of group therapy based on transactional analysis. But few studies have focused on examining the impact of this method on couple burnout and subsequently marital forbearance. Hence, the present study can fill the gap in this area. On the other hand, given the increase in the divorce rate of Iran and its association with marital burnout and forbearance, this research can provide a proper treatment method to reduce the rate of divorce or modify the lifestyle of families.

Thus, the aim of this study is to assess the effectiveness of psychotherapy based on transactional analysis in marital burnout and forbearance of female students.

3) Research methodology.

The present research was a semi-experimental study (pretest-post test design with unequal control group). The target population comprised all married female students studying in humanities subjects in Neishabur Islamic Azad University in the academic year 2015-16, who referred to the University Counseling Office during August to October in order to solve their marital conflicts. The research sample included 24 of these students, who were selected voluntarily and through available sampling method and were randomly assigned into two experimental and control groups. The experimental group received 10 one-half hour sessions of treatment based on transactional analysis while in the meantime; the control group received nutritional trainings. At first, both groups took a pretest and after the end of treatment, both groups took a posttest. The structure of transactional analysis sessions is as follows: 
First session: After introducing the group members, rules and regulations of the group were presented by the group leader. The process of the session involved the use of verbal and nonverbal messages and simple structural analysis of mental states (adulthood I, parenthood I and childhood I). The clients were asked to present a brief description of their situation, life history and interpersonal relationships.

Second session: In this session, the therapist discussed the history of Transactional Analysis and provided the conditions for the members to prepare for home assignments. Besides, each member reported a case of his own conversational relationship and the group members were asked to comment on the mentioned relationships. In the following, members were given homework (drawing ego gram).

Third session: Assignments of the group members were reviewed and the therapist presented a brief description of the book "The last situation and four mental states". The treatment process in this session included the existence of rules and role of communication rules in respect for self, others, friends and manner of self-expression. During this session, an assignment (drawing ego gram based on complex structural analysis) was given.

Fourth session: After reviewing the assignment given in the previous session, the group members became familiar with the role of communication patterns in personal and social life. Training of caressing and cross and complementary interrelationships was among the interventions of this session.

Fifth session: The previous session's assignment was reviewed. Involuntary reconstructions of childhood (childhood I) and basic life situations were fully described. Each member read two pages of the book "Mental games" by Eric Berne. Then, reconstructions of parental I were done in a simple language along with examples.

Sixth session: The members were asked to express the mental engagements they face. These engagements can include being far from family, business concerns in the future, student life, relationship issues with family and friends, marriage, exams and so on. The treatment process covered the training of reconstruction of the state of adulthood I. Then, the members were asked again to discuss their engagements and interactions and exchange their opinions. In this session, training of hidden relationships and double interactions and also an assignment together with some examples of hidden relationships were provided.

Seventh session: At the beginning of the session, the previous session's assignment was reviewed. Therapeutic intervention of this session included the training of four existential situations and healing of the child within. In this session, the group members were made to analyze the states of childhood, adulthood and parenthood and apply the manner of establishing a relationship between these states in their everyday behavior. Afterwards, an assignment was given to the members (questions and answers with dominant and non-dominant hand).

Eighth session: Initially, the previous session's assignment was reviewed. 
Then, the members experienced practical work (role-playing) and communication skills training. Also, each member who was willing to state his life stories talked about them. Besides, training time management concepts and methods of adult activation was among the interventions of this session. Finally, an assignment was given (determination of time management and use of adulthood I in one's behaviors).

Ninth session: Initially, the previous session's assignment was reviewed. Then, the group members presented some of their own mental states and current behaviors in the form of role-playing and feedback to each other. Inhibitors, drives and educational decision making were discussed.

Tenth session: At first, the previous session's assignment was studied. Questions were answered and the previous sessions were reviewed. In this session, all the therapeutic programs and purposes were examined and feedbacks about the progress of treatment and their reception were analyzed by the members. Therapeutic intervention of the last session included gaining executive power by adulthood I, applying the lessons learned from Transactional Analysis in group environments, family and society in order to achieve self-leadership.

Meanwhile, no specific psychological treatment was applied for the control group and the members of this group received only nutritional trainings. Before and after the implementation of the independent variable, all the subjects of experimental and control groups were evaluated through completing Couple Burnout Measure (CBM) and marital forbearance questionnaire.

4) Research tools.

Couple Burnout Measure (CBM): This scale was developed by Pines. This questionnaire consists of 20 items and its objective is to assess different aspects of individuals' citizenship behavior (altruism, conscientiousness, manliness, courtesy, kindness and civic virtue). This measure is a self-assessment tool that has been designed to measure the degree of marital burnout among couples. It includes three main components of physical fatigue (e.g., feeling of tiredness, lethargy and sleep disorders), emotional exhaustion (e.g., feelings of depression, hopelessness and entrapment) and mental exhaustion (e.g., feelings of worthlessness, frustration and anger towards spouse). All these instances are answered on a 7-point scale. Level 1 shows non-experience of the intended expression and level 7 represents extensive experience of the expression in question [5]. Reliability coefficient of Couple Burnout Measure has shown the internal consistency of the variables in the range of 0.84 to 0.90 [4].

Marital forbearance questionnaire: This questionnaire has been developed by Evans to assess marital for bearance. It includes 29 three-option items. For scoring this scale, the selected options that represent positive attitude are given zero; intermediate options received 2 points and the options indicating negative attitude were given 4 points. Low scores in this measure suggest high forbearance. Validity coefficient of this test through correlating the scores of this test with Aggression Test (AAi) was estimated to be around 0.33. Also, reliability coefficient of this test was reported to be 0.78 based on Cronbach's alpha method and 0.70 through split-half method (Table 1). 
Table 1. Mean and standard deviation of the pretest scores in questionnaires on marital burnout and forbearance.

\begin{tabular}{cccccc}
\hline Variables groups & Variable & Mean & Standard deviation & Minimum & Maximum \\
\hline $\begin{array}{c}\text { Experimental } \\
\text { group/pretest }\end{array}$ & Marital burnout & 2.6 & 1.1 & 0.9 & 4.8 \\
$\begin{array}{c}\text { Control } \\
\text { group/pretest }\end{array}$ & Marital burnout & 2.7 & 14.3 & 21 & 71 \\
Fxperimental & Morbearance & 44.4 & 13.7 & 1.09 & 4.8 \\
group/posttest & Forbearance & 35.7 & 9.7 & 28 & 71 \\
$\begin{array}{c}\text { Control } \\
\text { group/posttest }\end{array}$ & Marital burnout & 2.7 & 0.99 & 0.5 & 2.5 \\
\hline
\end{tabular}

\section{5) Research findings 。}

The results of analyzing the statistical assumptions revealed that both assumptions of equality of variances (using Levene test) and normality are established $(P<0.05)$. The first hypothesis indicated that "group therapy based on transactional analysis has an impact on marital burnout of married girl students". Table 2 shows the results of covariance analysis to test the above hypothesis.

As shown in Table 2, the main effect is significant $(P<0.05, \mathrm{~F}=6.1)$. Thus, the research hypothesis is confirmed. That is, group therapy based on transactional analysis has been effective in marital burnout. The amount of difference between the scores of experimental and control groups or the effect size of the training course is $\eta^{2}=0.19$. That is, $19 \%$ of the remaining total scores variance is influenced by group therapy based on transactional analysis (Table 3).

As can be observed in Table 3, the mean score of marital burnout questionnaire in the experimental group (1.7) was lower than that of the control group (2.6) after adjusting the scores, which indicates the effect of group therapy based on transactional analysis on marital burnout.

The second research hypothesis suggested that "group therapy based on transactional analysis has an impact on the forbearance of married girl students". Table 4 shows the results of covariance analysis to test the above hypothesis.

As shown in Table 4, the main effect is significant $(P<0.05, \mathrm{~F}=5.2)$. Hence, the research hypothesis is confirmed. That is, group therapy based on transactional analysis has been effective in the forbearance of female students. The amount of difference between the scores of experimental and control groups or the effect size of the training course is $\eta^{2}=0.17$. That is, $17 \%$ of the remaining total scores variance is influenced by group therapy based on transactional analysis (Table 5).

As can be observed in Table 5, the mean score of forbearance questionnaire in the experimental group (35.4) was lower than that of the control group (44.7) after adjusting the scores, which indicates the effect of group therapy based on transactional analysis on students' forbearance. It should be noted that in the 
Table 2. Summary of the results of ANCOVA test of posttest scores in marital burnout questionnaire.

\begin{tabular}{ccccccc}
\hline Source of changes & $\begin{array}{c}\text { Sum of } \\
\text { squares }\end{array}$ & $\begin{array}{c}\text { Degrees } \\
\text { of freedom }\end{array}$ & $\begin{array}{c}\text { Mean } \\
\text { square }\end{array}$ & F & $\begin{array}{c}\text { Significance } \\
\text { level }\end{array}$ & $\begin{array}{c}\text { Eta } \\
\text { coefficient }\end{array}$ \\
\hline Pretest & 10.9 & 1 & 10.9 & 70.9 & 0.000 & 0.73 \\
Main effect & 0.93 & 1 & 0.93 & 6.1 & 0.02 & 0.19 \\
Remaining error & 3.9 & 20 & 0.19 & - & - & - \\
\hline
\end{tabular}

Table 3. Mean of adjusted posttest scores in marital burnout questionnaire.

\begin{tabular}{ccc}
\hline Group & Mean & Standard deviation \\
\hline Experimental & 1.7 & 0.1 \\
Control & 2.6 & 0.1 \\
\hline
\end{tabular}

Table 4. Summary of the results of ANCOVA test of posttest scores in forbearance questionnaire.

\begin{tabular}{ccccccc}
\hline Source of changes & $\begin{array}{c}\text { Sum of } \\
\text { squares }\end{array}$ & $\begin{array}{c}\text { Degrees } \\
\text { of freedom }\end{array}$ & $\begin{array}{c}\text { Mean } \\
\text { square }\end{array}$ & F & $\begin{array}{c}\text { Significance } \\
\text { level }\end{array}$ & $\begin{array}{c}\text { Eta } \\
\text { coefficient }\end{array}$ \\
\hline Pretest & 3582.1 & 1 & 3582.1 & 153.7 & 0.000 & 0.86 \\
Main effect & 121.5 & 1 & 121.5 & 5.2 & 0.03 & 0.17 \\
Remaining error & 605.8 & 20 & 30.3 & - & - & - \\
\hline
\end{tabular}

Table 5. Mean of adjusted posttest scores in forbearance questionnaire.

\begin{tabular}{ccc}
\hline Group & Mean & Standard deviation \\
\hline Experimental & 35.4 & 1.2 \\
Control & 44.7 & 1.2 \\
\hline
\end{tabular}

forbearance test, high scores show lack of forbearance and low scores represent higher levels of forbearance.

\section{Discussion}

The present study was conducted to investigate the effectiveness of group psychotherapy based on transactional analysis in marital burnout and forbearance of married female students. The first hypothesis indicated that "group therapy based on transactional analysis has an impact on marital burnout of students". The research results demonstrated that the main effect is significant. Thus, the first research hypothesis is confirmed. That is, group therapy based on transactional analysis has been effective in marital burnout. These findings are consistent with the results obtained by other researchers [5] [6] [8] [9] [11].

In explaining this hypothesis, it can be said that marital burnout occurs due to a set of non-idealistic expectations and vicissitudes of life. Contrary to the views of most clinical approaches used in couple therapy, couples' burnout is not due to the existence of a fault in one or both of them or impairment in their rela- 
tionship.

According to [13], burnout is physical, emotional and mental exhaustion that arises from the mismatch between reality and expectations. Marital burnout is a set of unrealistic expectations from one's spouse and marriage which occurs along with stresses, realities and vicissitudes of life [14]. From the perspective of existentialism and psychoanalysis, burnout is an experienced state of physical, emotional and mental fatigue that results from the mismatch between expectation and realities [8]. According to [12], symptoms of burnout include general lack of enthusiasm, lack of satisfaction, emotional exhaustion, apathy and lack of interest. People suffering from burnout feel that they do not achieve the desired result despite great efforts. They may become angry sooner compared to the normal state and feel that they have lost their sense of humor and the ability to have fun.

Indeed, it cannot be said that just one factor has paved the way for burnout. Burnout begins with the growth of awareness and attention to the issues that are not as pleasant as in the past [8]. According to [5], a person does not become involved in burnout unless he is heavily engaged in an issue (like love and work). Therefore, group psychotherapy based on transactional analysis reduces marital burnout through an emphasis on general increase of enthusiasm, increased marital satisfaction, reduced emotional exhaustion and apathy, rising of couples' interest, decreased unrealistic expectations from one's spouse and marriage, adaptation to realities, reduced stresses and idealistic expectations, adjustment of life vicissitudes and matching expectations with realities on one hand and changing the communication style of subjects and building and strengthening assertive communication style on the other.

The second research hypothesis stated that "group therapy based on transactional analysis has an impact on the forbearance of married female students". The results revealed that the main effect is significant. So, the research hypothesis is confirmed. That is, group therapy based on transactional analysis has been effective in the forbearance of girl students. These findings are congruent with the results achieved in other studies [5]-[10]. They demonstrated that group therapy based on transactional analysis causes an increase in the forbearance and positive feelings and intimacy of couples. The study performed by Ahmadpour indicated that transactional analysis causes to increase forbearance and reinforce the components of happiness and psychological well-being, which is congruent with the findings of this research.

In explaining this hypothesis, it can be mentioned that increased forbearance is accompanied by negative affect including negative feelings and emotions such as guilt, shame, sadness, anxiety, worry and anger. Lack of marital forbearance suggests an aversive motivational system that is provoked by punishment. Through increasing forbearance, individuals live in a state of tranquility and relaxation. But people with low forbearance reflect a state of emotional pain and anxiety. Low-level depression and high pessimism characterize individuals with low forbearance. In high levels of stress, information processing is reduced so 
that stress decreases positive information and increases negative emotions to cope with the situation. It seems that transactional analysis approach affects the improvement of relationships by means of the techniques of identifying interrelationships and live draft and through the solutions it provides to change the live draft. Furthermore, this approach can reduce impatience, anger, depression and sadness through developing the perspective of individuals and changing their lifestyle and also changing the live draft. In line with verifying this hypothesis, we can refer to the study by [8] who demonstrated the influence of transactional analysis approach on increasing marital forbearance and reducing aggression. The research carried out by Khodaei revealed the impact of transactional analysis on reduced anxiety and increased forbearance. Another study done by [10] reported that transactional analysis approach can lead to reduced depression and increased forbearance in women with diabetes.

\section{Conclusion}

Since patience in sin is associated with the inhibition of sexual impulses, aggression, eating impulses, speaking passion and power and wealth orientations, forbearance refers to a kind of autonomy. Autonomy occurs when people use or leave actions, words and attitudes in order to achieve a result or avoid an outcome or the person being in a particular way or not. Transactional analysis approach raises the tolerance level of couples by increasing their marital forbearance and decreasing their conflicts. According to psychologists, an individual performs or leaves an action when this effort brings him pleasure or takes the suffering away from him. But the concept of forbearance cannot be subject to the pleasure principle because leaving pleasure also lies in the concept of patience and forbearance, particularly in relation to marital satisfaction and marriagerelated issues. Additionally, forbearance in the face of lust and sexual orientations can be raised in psychology under the concept of "self-control". This type of forbearance can be traced in psychology under the title of "psychological hardiness". Besides, patience in sin that requires the endurance of hardships and unpleasant events can be examined under the concept of "tolerance". It seems that transactional analysis approach affects the improvement of relationships by means of the techniques of identifying interrelationships and regulating the relations in marriage and also through the solutions, it provides to change the lifestyle. Also, this approach can increase self-control and psychological hardiness through developing the level of human awareness and understanding and changing people's lifestyle.

\section{References}

[1] Campbell, J.D., Trophell, P.D., Lavalle, L.F., Katz, I.M., Heine, S.J. and Lehman, D.R. (2006) Self-Concept Clarity: Measurement, Personality Correlates and Cultural 6 Boundaries. Journal of Personality and Social Psychology, 70, 156-171.

[2] Jahnsen, J.W. and Smith, E.R. (2006) Conceptualizing Social Identity. A New Framework and Evidence for the Impact of Different Dimensions. Personality and Social Psychology Bulletin, 25,120-135. 
[3] Kahn, R.H. (2008) The Effect of a Group Support Intervention Program on Depression, Social Adjustment and Self-Esteem of Adolescents in an Overseas American International School. The Catholic University of America. DAI-B 50/05, 1859.

[4] Kata, J. and Joiner, E. (2002) Membership in a Devalued Social Group and Emotional Well-Being: Developing a Model of Personal Self-Esteem. Collective SelfEsteem, and Group Socialization Sex Roles: A Journal of Research.

[5] Khaiiati, F. (1997) Examining the Rate of Efficiency of Self Esteem Training to Mothers' on Their Children's Self Esteem. M.A. Dissertation, Tehran Teacher Training University, Tehran.

[6] Lassiter, E. (2005) An Assessment of the Relationship between Student Perception of School Effectiveness and Student Achievement and Social Adjustment in Zoned Comprehensive Public High Schools. Morgan State University. DAI-A 55/07, 1767.

[7] Carver, R., Vunger, L. and Derry, D. (2003) Gender Identity and Adjustment in Middle Childhood-Sex Roles: A Journal of Research (August).

[8] Carver, R., Vunger, L. and Derry, D. (2004) Gender Identity and Adjustment in Middle Childhood-Sex Roles: A Journal of Research (Jun.).

[9] Elias, M.J. (2007) An Action Research Approach to Evaluation the Impact of a Social Decision-Making and Problem-Solving Curriculum for Preventing Behavior and Academic Dysfunction in Children. Evaluation and Program Planning, 14, 397 407.

[10] Florsheim, P.W. (2003) Family and Cultural Factors in the Psychosocial Adjustment of Chinese Adolescent Immigrants. Northwestern University. DAI-B 54/07, 3851.

[11] Falsafi Nezhad, M.R. (1993) Examining the Effects of Self Esteem on Students' Behavioral Adjustment 12-18 Years Old in Class Environment in Qum City. M.A. Dissertation. Teacher Training University.

[12] Goodstein, L.D. and Lanyon, R.I. (2005) Adjustment Behavior and Personality. Arizona State University, Tempe.

[13] Grahum, S. and Cockriel, B. (2004) Indexes to Assess Social and Personal Development and the Impact of College. College Student Journal, 30, 502-515.

[14] Greenberg, G.Y. (2001) The Effect of Relationship Enhancement Program on Marital Communication and Self-Esteem. Journal of Applied Social Sciences, 5, 78-94.

\section{Submit or recommend next manuscript to SCIRP and we will provide best service for you:}

Accepting pre-submission inquiries through Email, Facebook, LinkedIn, Twitter, etc. A wide selection of journals (inclusive of 9 subjects, more than 200 journals)

Providing 24-hour high-quality service

User-friendly online submission system

Fair and swift peer-review system

Efficient typesetting and proofreading procedure

Display of the result of downloads and visits, as well as the number of cited articles

Maximum dissemination of your research work

Submit your manuscript at: http://papersubmission.scirp.org/

Or contact ojmp@scirp.org 